\title{
ENHANCING STRATEGIC PLANNING THROUGH STRATEGY INSTRUCTION: THE EFFECT OF TWO TYPES OF STRATEGY INSTRUCTION ON LEARNERS' ORAL PLANNED PERFORMANCE
}

\author{
André Luís Specht ${ }^{1^{*}}$ \\ ${ }^{1}$ Universidade Estadual do Centro-Oeste, Irati, PR, Brasil \\ Raquel Carolina Souza Ferraz D’Ely ${ }^{2 * *}$ \\ ${ }^{2}$ Universidade Federal de Santa Catarina, Florianópolis, SC, Brasil
}

\begin{abstract}
This study aimed at investigating the impact of two types of strategy instruction on Brazilian learners' planned speech performance at the level of complexity, accuracy, fluency, and adequacy. In order to do so, three groups participated in the present study: (1) the integrated group received strategy instruction during their regular English classes; (2) the isolated group received strategy instruction in a separate course; and (3) the control group received no strategy instruction. The groups also performed two narrative tasks before and after treatment, preceded by 10 minutes of strategic planning. Learners' oral performance was analyzed and the statistical results showed that (i) the groups that received treatment outperformed the control group; and (ii) the isolated group produced more adequate and accurate speech, while the integrated groups improved their performance in terms of adequacy solely. In conclusion, one can claim that, in spite of the type of treatment, strategic planning can be enhanced by strategy instruction, shedding light on both Language Pedagogy and strategic planning research.
\end{abstract}

Keywords: Strategic Planning; Speech Production; Strategy Instruction

\footnotetext{
"Possui mestrado e doutorado na área de Linguística Aplicada pela Universidade Federal de Santa Catarina. É docente no Departamento de Letras da Universidade Estadual do Centro-Oeste na cidade de Irati-PR, onde também desenvolve pesquisas na área de ensino e aprendizagem de línguas estrangeiras. Seu e-mail é andreluisspecht@gmail.com. ORCID: https://orcid.org/0000-0001-9659-7793.

** Possui mestrado e doutorado em Linguística Aplicada pela Universidade Federal de Santa Catarina, onde também atua como docente. Seus temas de interesse são: ensino e aprendizagem de L2 numa perspectiva cognitiva, com foco no Ensino Baseado em tarefas para ambientes instrucionais e virtuais, e formação de professores. Seu e-mail é raqueldely@gmail.com. ORCID: https://orcid.org/0000-0003-2851-1868.
} 


\section{Introduction}

Within a task-based perspective, strategic planning is known as a pretask condition, which consists in providing students with time to plan a task prior to its actual performance (Ellis, 2005). In terms of research, strategic planning seems to be beneficial to oral performance, since students who had the opportunity to plan present more complex, accurate and/or fluent task performance (Skehan, 2016). In general, though, studies have not found the impact of strategic planning in all speech dimensions, since, according to Skehan and Foster (1996), one's attentional resources are limited and do not cope with focusing on complexity, accuracy and fluency at the same time, a phenomenon called trade-off hypothesis. Students who do not take many risks may produce less complex performance, while students who take more risks may produce less accurate performance (Skehan \& Foster, 2001). One or two dimensions may be prioritized at the expense of the (an)other(s), depending on a number of variables, such as type of task (Foster \& Skehan, 1996), amount of time for planning purposes (Mehnert, 1998), participants' level of proficiency (Kawauchi, 2005), to cite but a few.

Notwithstanding the trade-off hypothesis, some studies (D'Ely, 2006, for instance) did not show any statistical significant impact of strategic planning on speech performance, meaning that students who planned and those who did not presented similar performance in terms of complexity, accuracy, and fluency. One explanation for such a situation may be the lack of familiarity the students may have with the planning condition or the task (D'Ely, 2006; Ellis, 2009). In her study, D'Ely (2006) reports that one participant spent great part of the planning time attempting to recall a word he did not know how to say in English. This may suggest that the participant was not quite familiar with the pretask condition and did not know how to use it strategically, doing justice to its name.

Considering the familiarity issue, this article, which is the outcome of a doctoral study, aimed at investigating whether providing strategy instructions on how to plan causes an impact on a group of Brazilian students' oral performance at the level of complexity, accuracy, fluency, and adequacy. Two types of strategy instruction were administered in order to create a stronger interface with the foreign language classroom. The isolated type of strategy instruction was administered outside the regular English classroom, while the integrated one was administered within the regular English classroom. For the sake of organization, this article is divided into five main sections; (1) this introduction; (2) review of literature; (3) method; (4) results and analysis; and (5) final remarks.

\section{Review of literature}

\section{Strategic planning}

Strategic planning, within a task-based perspective, consists in providing some time for learners to plan their tasks prior to the actual task performance 
(Ellis, 2005). However, defining strategic planning only as an opportunity-to-plan condition may be simplistic and structural and would omit the complexity of the cognitive and metacognitive processes learners may engage in during the pretask phase. That being said, it is possible to state that strategic planning provides learners with more than an amount of time to plan, it provides learners with the opportunity to reflect upon the message they may deliver, the way they may deliver this message, the words they may use for this message. In fact, it "is essentially a problem solving activity; it involves deciding what linguistic devices need to be selected in order to affect the audience in the desired way" (Ellis, 2005, p. 3).

When planning an oral task, learners need to activate task-relevant information, maintain it activated and accessible until this information can be integrated to subsequent information in a coherent way; learners also need to sustain, maintain, and switch attention from the various components of the task (e.g., from meaning to form and vice-versa), suppress irrelevant L2 and L1 information, and monitor (Guará-Tavares, 2008, p. 180).

Furthermore, with the opportunity to plan, learners may also make use of strategies that may assist them in planning their speech performance such as organizing the sequence of the speech, rehearsing the speech, to cite but a few (Guará-Tavares, 2016; Ortega, 1999; 2005; Pang \& Skehan, 2014; Specht \& D’Ely, 2017).

Moreover, D'Ely (2006) draws our attention to the fact that the definition of strategic planning is not quite clear in the Second Language Acquisition (SLA) field. She explains that "(...) research on planning has stemmed from two separate but related fields: learning strategies and task-based instruction (p. 27)”. In the former, planning is conceptualized as metacognitive strategy, which may be consciously used by learners in order to regulate their learning and language use (Cohen, 1998). In terms of a task-based perspective, planning is identified as a pedagogical tool, which can be made available to learners as a pretask condition. In other words, strategies correspond to action taken by learners, while conditions are prerequisites of a task. During strategic planning, for instance, learners may even use planning as a metacognitive strategy along with other strategies (Ortega, 1999; 2005, Guará-Tavares, 2016; Pang \& Skehan, 2014).

Structurally, the way strategic planning is manipulated, as a pretask condition, can have variations, meaning that the opportunity for planning can be manipulated and divided into two other categories. Learners may simply be given some time to plan their tasks or they can receive some advice on how they can do it, resulting in two different types of strategic planning: unguided and guided planning, respectively. ${ }^{1}$ Regardless of the categories, learners can plan their tasks individually, collaboratively in small groups and/or with the teacher's assistance (Ellis, 2005, p. 5 ), which opens more room for pedagogical intervention and research inquiry.

This possibility for pedagogical intervention and research inquiry makes the concept of strategic planning quite promising. It can be used for pedagogical and 
research purposes, informing both Language Pedagogy and Second Language Acquisition areas, which consequently may build an interface between them (Ellis, 2005). ${ }^{2}$ From a teaching perspective, strategic planning may lead learners to focus their attention on formal aspects of language within a meaning-driven context. This movement is known as focus on form (Long, 1991) and is seen as a key ingredient for acquisition to take place (Long, 1991; Schmidt, 2001). Interested in this movement, Ortega (1999) investigated whether, indeed, time for planning might lead learners to focus on form, and she was able to provide positive results regarding that. Therefore, it may be suggested that when planning, learners may also be learning.

From a theoretical perspective, strategic planning has been adopted as a construct to investigate L2 oral performance. Mostly, researchers have conducted studies in order to scrutinize the benefits of strategic planning to L2 oral performance, and the results seem to be positive. In other words, providing time for learners to plan their task causes a positive impact on their oral performance. However, there is still need for further investigation in order to understand the phenomenon as a whole and to reinforce the connections with the theories and models that strategic planning is theoretically grounded on (Skehan, 2014).

In short, it is possible to conclude from the discussion that strategic planning is not simply a time opportunity for task preparation; it is a pedagogical tool, manipulated in the form of a pretask condition, in which learners are exposed to and may take advantage of it in order to prepare their tasks. This preparation may lead to an improvement in the task performance as well as open the opportunity for learners to focus on form. Furthermore, task planning may lead learners to engage in cognitive and metacognitive processes.

\section{Assistance for strategic planning}

The idea of reinforcing the planning time by providing some type of assistance is not unusual in the area and can be seen as "a potentially crucial learner variable" (Ellis, 2009, p. 491). As a matter of fact, the core idea of guided planning, for instance, revolves around the concept of instruction. The difference resides in the intensity of instructional treatment and its objective. In Foster \& Skehan (1996), the objective was to understand the difference of guided and unguided planning, and whether there were differences between the two conditions. Foster and Skehan (1999) introduced the idea of teacher-led planning, in which the teacher has a role in the process of planning. Sangarun (2005), on the other hand, aimed at understanding whether offering instruction which focused on form, meaning or both would cause a different impact on learners' performance. Kauwachi (2005) investigated the use of different activities while planning: reading, writing and listening. D'Ely (2011) emphasized the role of the teacher in leading learners for planning purposes. And, finally, in Specht and D'Ely (2017), the objective was to teach learners how to use planning time more efficiently. 
Even though the studies' results seem to provide positive evidence on the effect instruction has on strategic planning and on speech performance, they do not present a clear picture of the oral dimensions affected. Foster and Skehan (1996) claimed that the group who received instruction (guided planning) produced more fluent and complex language, but no impact on accuracy was found. The authors explained that such a result may be due to a trade-off effect. In Foster and Skehan (1999), on the other hand, results showed that teacher-led planning promoted a great impact on accuracy, in addition to helping students produce a more balanced performance. The authors explained that the teacher can "channel attention and (...) ensure that the language used in the task makes a pedagogic contribution" (p. 238), optimizing the planning time and leading learners to produce more accurate language. Similar results were also found in D'Ely (2011) and in Specht and D'Ely (2017). In D'Ely (2011), the groups that performed the tasks under teacher-led planning did not show any improvement in terms of fluency and complexity; however significance was approached for accuracy. The same occurred in Specht and D'Ely (2017). Their participants produced less error-free clauses after instructional sessions. The authors, though, did not analyze other speech dimensions.

Sangarun (2005) pointed out that there was an overall improvement in terms of fluency, complexity and accuracy for the three experimental groups (focus on form, focus on meaning, and focus on form/meaning). However, the author explained that, even though there was no difference among the groups, the meaning/form group was remarkably the most balanced condition, because they were able to convey clear information and organization. "Strategic planning directed at combined meaning/form appears to be relatively more effective than planning that is focused separately on meaning or form" (p. 129). Similar results were also found in Kawauchi (2005). No difference was found among the three activities (reading, writing, and listening) adopted during planning time. Nevertheless, it seemed that participants that engaged in reading while planning used more embellished words that were presented in the reading they were exposed to, while the same was not seen in the writing and rehearsing groups.

Shortly, it is possible to observe that instruction on how to plan has been operationalized in different manners, such as guided planning, teacher-led planning, and strategy teaching, which may be the reason for such different impacts on speech performance. Nonetheless, all in all, results show that providing learners with some type of instruction in order to enhance the strategic planning condition seems to have a positive impact on learners' speech performance when compared to a non-planning condition and/or to a planning condition without any assistance. Instruction, in general, seems to lead learners to use the planning time more strategically. 


\section{Method}

\section{Objectives and Research questions}

The present study aimed at investigating the impact of two types of strategy instruction - integrated and isolated - on a group of Brazilian learners' planned performance in terms of fluency, complexity, accuracy and adequacy. In order to achieve such an objective, the following research questions guided the study:

a. Does strategic planning after instructional sessions produce an impact on students' L2 oral performance at the level of fluency, complexity, accuracy, and adequacy, regardless of instruction type?

b. Is there a difference between the two types of instruction - isolated and integrated - in terms of benefits, if any, for planned speech performance?

\section{Groups and Participants}

Students from three level-5 groups of Extracurricular course at UFSC ${ }^{3}$ were invited to participate in this study. These groups had the researchers of this study as regular teachers. Each group had 20 students, but only those who achieved an intermediate level of proficiency in an oral proficiency test (D'Ely \& Weissheimer, 2004) were taken as participants, yielding two groups with 11 participants each and another group with 12 participants. All the participants signed a consent term. The three groups were randomly assigned to a type of treatment: isolated, integrated and control. The isolated group received treatment apart from the English regular lessons; the integrated group received treatment within their regular English classes; and the control group did not receive any treatment whatsoever.

The participants filled in a background questionnaire, which provided their profile regarding age, profession, and impressions on English language. Participants' age varied from 17 to 55 years old, being 13 participants under 20 years old, 17 participants between 20 and 29 years old, and 4 participants over 30 years old. Most participants were undergraduate and graduate students, but there was also a beautician, a business assistant, a professor, a musician, a visual artist, a firefighter, and a journalist. In general, most participants considered their speech performance as weak and they claimed that speaking is the most difficult language ability.

\section{Instruments}

\section{Tasks and conditions}

Two then-and-there picture-cued narrative tasks were administered in the study: one before and another after the treatment, which lasted a period of 3 weeks. The control group did not receive treatment, so they just performed the 
tasks. Such type of tasks was adopted, because they (a) seem to be popular and efficient in strategic planning studies (Ortega, 1999), (b) elicit performance that can be analyzed in terms of complexity, accuracy and fluency (D'Ely, 2006), (c) can be manipulated monologically (Kawauchi, 2005); and (d) were previously piloted (Specht, 2015). In addition, their then-and-there nature, that is, the lack of support during planning and retelling the story, leads "(...) learners to use their full range of communicative resources” (D’Ely, 2006, p. 96), making this type of task more complex and cognitively demanding (Robinson, 1995).

The first task was related to a story of a man who appears at the house of his beloved with a different gift every time, but he is always rejected by her. In the end, she becomes jealous because he finds another girl. The second task was related to a story of Tom (from the cartoon 'Tom and Jerry'), who falls in love with a female cat, but he has to dispute her love with a richer cat. In the end, the female cat marries the richer cat, which makes Tom depressed.

The participants were given 50 seconds to assimilate the story - which has been the amount of time used in some studies (D'Ely, 2006; Guará-Tavares, 2016; Specht \& D’Ely, 2017, for instance). After that, they had 10 minutes to plan their speech - which seems to be a standard amount of time in planning studies (Ellis, 2009). For the planning condition, participants were only given a sheet of paper and a pen for draft purposes; however, they did not have access to the story anymore, and they did not receive any information on what to plan (even in Task B, which was administered after instruction). Finally, after planning time, they had to retell the story with no support of the narrative or the planning draft. Moreover, students were instructed on how to use the digital recorders, and they were told they could speak as much as they wished; however, they could not pause the story under any circumstances.

In addition, right after the performance of each task, participants were asked to fill in a posttask questionnaire, which aimed at controlling their use of strategies and understanding their perception on the pretask phrase and the task performance. In the questionnaire administered after the performance of the second task, for the experimental groups, questions related to the instructional sessions were also included. Such instruments were adopted in this study following D'Ely (2006), as a way to collect additional information that could illuminate the data analysis.

\section{Instructional interventions}

The instructional sessions, both the integrated and the isolated ones, were designed by following the strategy training framework proposed by Oxford (1990), which basically consists in (a) presenting a set of strategies to the students and (b) practicing them through activities. The strategies chosen for the sessions were those used by Specht and D'Ely (2017): organizational planning, monitoring, rehearsal, writing/outlining/summarizing, elaboration, lexical search, and paraphrasing. Such a decision was made considering that Specht's sessions also aimed to help students become more strategic in performing the pretask 
activity (strategic planning). Those specific strategies were reported by GuaráTavares' (2016) participants as being the ones most used during the planning condition. Some of the strategies were cognitive strategies such as lexical search and monitoring; however, for the purpose of this study, they were manipulated in order to serve as metacognitive strategies.

In the integrated group, the strategy sessions were manipulated during the regular English classes, right before an oral activity. Students were presented with one or two strategies to be used for that specific activity; they practiced them by doing the activities; and after that, they reflected on their use. The strategy sessions lasted 3 weeks, in six classes, considering that students had two one-anda-half-hour classes every week. In the isolated group, participants received a oneand-a-half-hour strategy session (the period of an entire regular English lesson) in the second week after the performance of the first task. The session focused on the presentation, practice and reflection of the strategies, one by one.

\section{Data collection}

First, participants signed up the consent form and filled in the profile questionnaire in class, and then, they were taken to the language laboratory to perform the first task. After receiving the instructions and planning the task, they recorded their story using an audio recorder. During a period of three weeks, the experimental groups received their respective instructional treatments, while the control group had regular English classes. It is worth recalling that the regular classes and instructional sessions were taught in the three groups by the researchers of this study. After the treatment phase, participants were taken to the language laboratory to perform the second task. The procedures were the same adopted in the first task. Moreover, during the entire process, the researcher kept a diary to write down relevant information that he perceived and that was shared by the participants.

\section{Data Analysis}

\section{Measures to assess speech performance}

Participants' oral performance was transcribed and assessed in terms of complexity, accuracy, and fluency, which are the most traditional speech dimensions in the area (Skehan, 2014). For each dimension, measures were adopted.

For Complexity, two measures were adopted. (1) Degree of subordination was calculated by dividing the number of independent and dependent clauses by the number of AS-units. The result represents the index of subordination in the speech sample. If the index number is 1 , it means that the story does not have any subordination - and the higher this number, the higher the number of subordination in the story. (2) Number of words per AS-unit considered the number of words divided by the number of total AS-units. Repetitions, reformulations and self-repairs were not counted as words. In addition, contractions were calculated as two different words. 
Considering Accuracy, three measures were adopted. (1) Percentage of errorfree AS-units was calculated by dividing the number of error-free AS-units by the total number of AS-units. The result was, then, multiplied by 100. (2) Number of errors per 100 words was calculated by dividing the total of errors by the total of words, and the division result was multiplied by 100. Repetitions, replacements, and self-repairs were not counted as words. (3) Average of errors per AS-units was calculated by dividing the number of errors by the number of AS-units. An error was defined as any linguistic form or combination of forms that deviate from the standard grammar. However, some specific speaking characteristics were taken as exceptions, such as adverbial placement and pronunciation errors when considered intelligible by raters.

Regarding Fluency, five measures were adopted. $(1,2)$ Speech rate pruned and unpruned aimed at providing the number of words per minute; however, the first was a more specific measure, because it did not consider repetitions, reformulations and self-repairs as words, while the second did. Their calculation was provided by dividing the number of words by the total amount of time in seconds, and the result was multiplied by 60. (3 and 4) Number of middle and boundary clause unfilled pauses was calculated by dividing the total pausing time (middle or boundary) in seconds by the total audio time in seconds. One second was used as a cutoff point. (5) Number of self-repairs was calculated by dividing the total self repairs by the number of AS-units. Self-repairs were considered any reformulation, repetition, false starts, or replacements participants produced while narrating the story.

Additionally, adequacy (Pallotti, 2009) was included as an extra dimension in order to assess a more discourse-oriented perspective of speech performance. For adequacy, three raters (Brazilian graduate students with extensive teaching experience) listened to the participants' stories and scored them regarding (a) structure, (b) clarity, (c) appeal, (d) vocabulary, and (e) fluency. Each topic could be scored between 1 and 5 ( 1 very poor and 5 very good). The final adequacy score was the sum of the 5 topics. Following, a Cronbach's Alpha test was run in order to check for inter-rater reliability. The correlation number obtained was .783, which demonstrates that the raters' scores followed a similar evaluative pattern. Finally, a mean of the three scores was the score used for statistical purposes.

\section{Statistical treatment}

In order to verify whether all the 11 measures (Table 1) were assessing different aspects of speech performance, a Principal Component Analysis test was run. The test result showed that the four dimensions loaded in different components, which indicates that the four dimensions account for specific purposes in the analysis. All the measures were, then, submitted to statistical treatment. Mixed ANOVA tests were run - one for each measure - in order to understand whether the possible differences within- and between- group comparisons were statistically significant or not. 
Table 1 - Dimensions, measures, and their references in the statistical reporting tables

\begin{tabular}{lll}
\hline Complexity & Subordination index & C1 \\
& Number of words in AS-unit & C2 \\
Accuracy & Percentage of error-free clauses & A1 \\
& Errors per 100 words & A2 \\
& Average of errors per AS-unit & A3 \\
Fluency & Speech rate unpruned & F1 \\
& Speech rate pruned & F2 \\
& Number of end unfilled pauses & F3 \\
& Number of mid unfilled pauses & F4 \\
& Number of self-repairs per AS-unit & F5 \\
Adequacy & Functional adequacy & Ad1 \\
\hline
\end{tabular}

\section{Results and discussion}

\section{Quantitative analysis - Mixed ANOVA}

Mixed ANOVA is a statistical test used to examine whether the differences between- and within-group comparisons are significant. Table 2 shows the results of the interactions between the two tasks and the three groups.

Table 2 - Tests of Within-Subject Contrasts

\begin{tabular}{llllllll}
\hline Source & Measure & F value & Sig. & Source & Measure & F value & Sig. \\
\hline Tasks & C1 & .074 & .787 & Task ${ }^{\star}$ Groups & C1 & 2.041 & .147 \\
& C2 & .353 & .557 & & C2 & .585 & .563 \\
& A1 & 2.526 & .122 & & A1 & 3.714 & .036 \\
& A2 & 3.654 & .065 & & A2 & 2.218 & .126 \\
& A3 & 4.971 & .033 & & A3 & 1.757 & .189 \\
& F1 & .330 & .570 & & F1 & .206 & .815 \\
& F2 & .043 & .838 & & F2 & .447 & .644 \\
& F3 & .211 & .649 & & F3 & 1.088 & .350 \\
& F4 & 2.346 & .136 & & F4 & .132 & .877 \\
& F5 & .623 & .436 & & F5 & 1.380 & .267 \\
Ad1 & 2.971 & .095 & & Ad1 & 6,152 & .006 \\
\hline
\end{tabular}

As can be seen in bold, there were three significant differences in the interactions for measures $\mathrm{A} 1(\mathrm{~F}=3.714$ - p. 0.036), $\mathrm{A} 3(\mathrm{~F}=4.971$ - p. 0.033), and $\operatorname{Ad} 1(\mathrm{~F}=6.152$ - p. 0.006), and one interaction that approached significance for measure A2 ( $F=3.654$ - p. 0.065). However, no significant differences in the interactions for complexity and fluency were found or even approached. Therefore, it is possible to claim that there were only significant differences in terms of accuracy and adequacy when comparing the three groups and the two tasks they performed.

In order to scrutinize the significant differences, especially considering that the performance analysis concerning the accuracy measures were not completely 
apparent, an additional command was added to the syntax of Mixed ANOVA test in SPSS, and between- and within- pairwise comparison tables were provided. Tables 3 and 4 show, respectively, the results of the group and task comparisons.

Table 3 - Groups comparison - Task B

\begin{tabular}{llll}
\hline Measure & Groups & Groups & Sig. \\
\hline Ad1 & Int & Iso & 1.000 \\
& & Con & .025 \\
& Iso & Int & 1.000 \\
& & Con & .005 \\
& Con & Int & .025 \\
& & Iso & .005 \\
\hline
\end{tabular}

Table 4 - Pairwise Comparison - Comparison of Tasks A and B in each group

\begin{tabular}{llllll}
\hline Measure & Groups & Sig. & Measure & Groups & Sig. \\
\hline A1 & Int & .262 & A2 & Int & .524 \\
& Iso & $\mathbf{. 0 1 0}$ & & Iso & $\mathbf{. 0 6 0}$ \\
& Con & .290 & & Con & $\mathbf{. 0 5 8}$ \\
A3 & Int & .797 & Ad1 & Int & .136 \\
& Iso & $\mathbf{. 0 3 1}$ & & Iso & $\mathbf{. 0 0 4}$ \\
& Con & $\mathbf{. 0 8 0}$ & & Con & $\mathbf{. 0 8 6}$ \\
\hline
\end{tabular}

As can be seen in Table 3, the only significant difference between group comparisons was at the level of adequacy between the pairwise groups: Con/Int $(\mathrm{p}=.025)$ and Con/Iso $(\mathrm{p}=.005)$ in Task B. This indicates that the performances of the groups that received treatment were more adequate than the performance of the group that did not. Moreover, it is worth mentioning that no significant differences between the performances of the groups in Task A (the task which was performed under the same condition for the three groups) were found. This suggests, therefore, that the groups produced similar outcomes in terms of complexity, accuracy, fluency, and adequacy, in spite of the differences reported in the descriptive statistics analysis. This similarity in the performance of Task A reinforces (i) homogeneity regarding the proficiency level of the participants, which was previously controlled in this study as well as (ii) reliability in comparing groups' and tasks' performances.

Table 4 shows that the only group that improved its performance from Task A to Task B was the Isolated group. The group presented significant improvement in two accuracy measures (A1 and A3), and the adequacy measure. In addition, it also approached significance in the third accuracy measure (A2). Some near significant results were found for the control group at the level of accuracy (A2 and A3) and adequacy as well. However, as concerns adequacy, the control group produced a less adequate performance in Task B compared to Task A; while in Task A, the group's score was 16.8, in Task B, it was 15.3. Thus, it can only be said that a tendency of improvement in terms of accuracy is seen in the performance 
of the control group. And finally, no significant improvement was found in the performance of the Integrated group.

In short, the results of Mixed ANOVA show that the Isolated group outperformed the other two groups in terms of accuracy and adequacy, being the impact of the latter found in both within- and between-group comparisons - which reinforces the nature of the impact. The Integrated group, in their turn, outperformed the control group in terms of adequacy, when their performance in Task B was compared with that of the control groups. And the control group produced the lowest performance, since no significant improvement was found. The control group, though, approached significance in two accuracy measures and the adequacy measure, which may indicate an improvement at the level of accuracy and a decrease at the level of adequacy in Task B. All in all, these results may indicate that the two types of treatments, even though they presented different levels of improvement, may have a positive effect on strategic planning and, as a consequence, on speech performance.

\section{Discussion}

In general terms, it is possible to claim that instruction had, indeed, a role on planned speech performance in this study, and that it could be administered both within regular English lessons and as an isolated lesson. Furthermore, the use of adequacy seems to be an efficient measure in assessing aspects of oral production, not grasped by the traditional measures - complexity, accuracy, and fluency. In spite of the enlightening results, there are still some issues that must be further explained and discussed under the light of the theoretical framework adopted by this study.

Initially, considering the two types of instruction administered in this study, it was possible to observe that both of them (integrated and isolated) caused an impact on planned speech performance, which may suggest that instruction has a role on enhancing strategic planning, thus, improving, as a consequence, speech performance, as pointed out previously. Although the field of strategy instruction does not have enough evident support regarding the efficiency of strategy instruction and acquisition (Dörnyei, 2005), such a result is important to reinforce the positive role of strategy instruction on, at least, improving speech production, especially when considering that the few but all studies on strategy instruction and speech production have presented positive evidence so far. However, notwithstanding the positive result, each type of instruction did not seem to affect speech performance with the same strength. Isolated instruction caused an impact on speech performance at the level of both accuracy $(\mathrm{p}=.01$ $-\mathrm{A} 1 ; \mathrm{p}=.031-\mathrm{A} 3$ within-group comparison) and adequacy $(\mathrm{p}=.005$ and $\mathrm{p}$ $=.004$, between and within group comparisons respectively), while integrated instruction only affected adequacy ( $\mathrm{p}=.025$ between-group comparison).

This difference may indicate that isolated strategy instruction had a stronger effect in comparison to the integrated one. A possible explanation for 
that may be related to the degree and the amount of attention that each type of instruction demanded from learners. The strategy instruction delivered to the integrated group was manipulated to be part of their regular English classes, administered during the oral activities. Prior to each oral activity, learners were given some time to plan and were told how to plan it, and after the activities, learners were led to reflect upon the use of the strategies. In opposition, the isolated group spent an entire lesson working with strategies they could use for planning purposes. The learners were presented to the strategies one at a time, and for each strategy they performed an activity specifically designed for the strategy's practice. It is clear that the emphasis on strategy teaching was higher for the isolated group, which may have led learners to focus more attention on the strategies, thus learning them faster, as explained by advocators of isolated strategy instruction (Trendak, 2015). In addition, even though both types of instruction aimed at presenting, practicing and discussing the strategies explicitly, having an entire lesson available to work with the strategies seems to highlight the importance of the content.

Nevertheless, no study, to the best of our knowledge, has investigated the difference between the two types of instruction in order to understand which one is more efficient. Oxford (2011) only mentions examples of isolated and integrated strategy instruction programs and points out that all of them are successful in promoting better language learning and performance. However, studies, properly speaking, that investigated the impact of strategy instruction on oral performance adopted isolated types of instruction, which allows more control of the experiments. ${ }^{4}$ This discussion remains on hypothetical terms, strongly driven by pedagogical reasons. Advocators of the isolated type of instruction claim that focusing learners' attention on solely learning strategies leads them to learn faster, as pointed out previously; while advocators of the integrated type of instruction explain that inserting strategy instruction within regular classes is a more organic way of teaching strategies and may lead learners to assimilate the strategy better, since they would learn a specific strategy when they really needed it. Nonetheless, regardless of the differences, both types of instructions produced an impact on speech performance, at least considering immediate effects. More research would be necessary to understand the lasting effects of this impact.

It is worth highlighting, though, that the impact of the integrated instruction was only possible to be identified by the adoption of adequacy as an extra measure to assess speech performance. If only complexity, accuracy, and fluency measures had been used, no difference between the integrated and the control groups would have been found. This would have been considered a lack of efficiency for the integrated instruction, and by all means it was not the case. When analyzing the task outcomes, the treatment groups presented stories that were better structured in Task B, and this aspect of speech performance was only possible to be brought into view and identified with the adoption of adequacy, which has proven, at least in this study, to be an efficient measure, representative of an extra speech dimension. Speculatively, one may wonder 
whether the studies on strategic planning that did not show any impact of the pretask condition on speech performance in terms of the traditional measures improved on different aspects that were not covered, such as a clear outcome with a better structured text. In addition, it is important to highlight that the fact that stories were better, overall, might indicate that learners' primary focus is on meaning rather than on form (VanPatten, 1990), which has been advocated in the field of Task-based approach.

Even though the general impact of the instructional sessions seems to be on adequacy, it must not be forgotten that the isolated group also improved their accuracy level, that is, they produced fewer mistakes in Task B compared to Task A. This indicates that learners used their attentional resources both to deliver a well structured story and to monitor their speech during online performance. Even if speculatively, this also may be an indication of a trade-off effect between complexity and accuracy. Although no significant result was found for complexity, the Isolated group decreased their number of subordinate clauses from Task A to Task B as it was presented by means of the descriptive analysis (from 1.44 to $1.32^{5}$ ). Skehan and Foster (2001) explain that when learners are concerned about not making mistakes, they avoid using more elaborated language. By the same token, in contexts where learners do not seem to be worried about making mistakes, they tend to produce more elaborated language.

Moving the discussion to a strategic planning perspective, studies on the area have brought varied results regarding the impact of the pretask condition on speech performance. In general, fluency seems to be the most affected dimension, while there is a trade-off effect between complexity and accuracy, in which the latter seems to have less impact (Ellis, 2005; 2009). In this study, the Mixed ANOVA's results, more specifically considering the impact on accuracy, did not follow this pattern. The Isolated group did not improve their performance in terms of fluency and complexity, which can be a suggestion of a trade-off effect, as pointed out in the previous paragraph. Nevertheless, other explanations may be suitable as well.

At first sight, this deviation from the standard results in the area would be expected, since this study did not have a non-planning condition as a comparative basis like other studies in the field. There was a contrast between an unguided strategic planning condition and an instructed but still unguided strategic planning condition. Therefore, no claim on the difference between non-planning and planning conditions can be raised here, as it was done by Specht and D'Ely (2017), for instance. In their case, the participants performed three narrative tasks under three conditions: non-planning, planning, and planning after instruction. There was no difference between the non-planning and planning conditions in terms of accuracy, which means that providing time or not for planning does not affect accuracy. In this study, on the other hand, all the performances, Tasks A and $\mathrm{B}$, were planned, which does not open room to recognize whether participants benefited from the planning condition in Task A or not. 
However, in spite of having or not benefited from strategic planning in Task $\mathrm{A}$, it is possible to observe that the treatments, especially the isolated one, assisted learners in improving the use of the planning condition, and as a consequence, it produced an impact on the groups' speech performance. This, by itself, may suggest that learners were not taking advantage of the pretask condition at its best in Task A, regardless of the impact strategic planning may have had on Task A. Qualitative results indicated that learners may have benefited from strategic planning in Task A. Most participants claimed that the pretask condition was positive to the task performance, recognizing that, without it, the task would have been much more difficult. However, at same time, some participants explained that the planning time confused them in Task A. Such a complaint was not found in the post-task questionnaires B.

Notwithstanding the methodological issue presented previously, the impact on accuracy observed in the Isolated group seems to follow the pattern of a few studies that provided their participants with some type of instruction on how to plan. In special, the results corroborate Foster and Skehan (1999), D'Ely (2011), and Specht and D'Ely (2017). These studies have shown that enhancing strategic planning may lead to an impact on accuracy. Both Foster and Skehan and D'Ely dealt with teacher-led planning, while Specht and D'Ely, like this study, provided learners with isolated strategy instruction on how to plan. It seems that, as pointed out by Foster and Skehan (1999), the role of a mediator (in the studies' case, a teacher) channels learners' attention to focus on the language used in the task. In this study, specifically, strategies such as monitoring and paraphrasing have the purpose of making participants reflect upon the language they would use in the task, which corroborates Foster and Skehan's explanation.

It seems that strategy instruction on how to plan has a relation with teacherled planning, at least considering the impact on accuracy. In Foster and Skehan's case (1999), the teacher-led group produced more accurate language regarding the percentage of error-free clauses compared to the group that planned individually and without any instruction, which can be related to the results presented in this study. Foster and Skehan explained "(...) that a teacher-organized planning session does lead to more control over the language used" (p. 239). Even though, in this study, participants did not receive teachers' assistance during planning time, they received training sessions on how to plan. These training sessions provided them with strategies that assisted them in getting more control over the use of language, similar with a teacher-led planning. Foster and Skehan highlight that teacher-led planning "is more standardized; and it is likely to introduce a greater level of efficiency to all learners since it is the product of preparation on a teacher's part, and a greater degree of organization" (p. 223). In a way, when a teacher teaches learners specific strategies they may use for a specific task, he or she is providing a pattern on things that are possible to do, which also brings a degree of organization.

These similar results may also suggest some pedagogical reflection upon the role of the teacher during planning time. Clearly, in the classroom, there is 
space for both types of planning: teacher-led and instructional sessions; however, strategy instruction provides tools for learners to pursue activities and reach objectives on their own, becoming less dependent on the teacher, which is the goal of instruction after all. Moreover, strategy instruction also promotes reflections on language use in general, equipping learners with strategies that they may also use in their daily lives.

By performing a similar task, learners attempted to overcome difficulties and problems they had in the first task. The treatment groups could benefit from the strategies and the reflection that the instructional sessions promoted, while the control group was left on their own. Even though the control group's intention was to present a better story compared to the first one, they ended up using similar strategies they used in the first task. An interesting phenomenon was the reduction of the story. In general, the control group presented briefer stories, which may have been a strategy they adopted to cope with recalling what they had planned. During the collection of Task B, some participants from the control group claimed that a better story is a briefer one. ${ }^{6}$

Even though, no significant results were found for the control group, significance was approached for two measures of accuracy, and at the same time, there was a decrease in adequacy. Some speculative explanations may be possible here. Even though the control group did not receive any type of instruction, they performed two similar tasks both under planning condition. The improvement in terms of accuracy may have been a result of task familiarity. Another reason may be their poor performance in Task A, which opened more room for improvement. Considering percentage of error-free clauses in Task A, for instance, the control group presented only $26 \%$ of error-free clauses, while the isolated and the integrated group 35\% and 39\%, respectively. Finally, there may be a trade-off effect between accuracy and adequacy, considering that they produced a less adequate performance in Task B.

The other studies that offered some type of assistance for strategic planning do not seem to follow the same pattern regarding the impact on accuracy. Foster and Skehan (1996) did not present any difference between the group that received metacognitive advice on how to plan compared to the one that did not. Sangarun (2005) did not show any difference between the groups that received instruction on form, meaning, and form/meaning; however, he pointed out that the form/ meaning group presented a more balanced performance. As regards Foster and Skehan (1996), the guided group presented an impact on fluency and complexity, which may have decentralized their attention from accuracy. In addition, unlike D’Ely (2011), Foster and Skehan (1999), and Specht and D'Ely (2017), which provided a more general and enveloping assistance, Foster and Skehan (1996) and Sangarun (2005) offered more shallow and directed orientations, respectively.

Finally, one last issue that must be taken into consideration when understanding the impact of strategic planning and/or strategy instruction on how to plan, even if speculatively, is learners' L2 linguistic knowledge. In this study, participants had an intermediate proficiency in English, their L2, and they 
did not receive any type of linguistic assistance when going through strategic planning and the task performance itself. They made use of their own linguistic resources. D'Ely (2006) explained that the amount of linguistic knowledge a learner has may have an impact on how they perform a task. In this sense, their linguistic competence may determine "the extent to which learners may perform better" (p. 206).

\section{Final remarks}

All in all, this study - which aimed at investigating the impact of two types of strategy instruction on learners' oral performance in terms of complexity, accuracy, fluency, and adequacy - comes to the following conclusions: (1) The two types of strategy instruction, integrated and isolated, seemed to assist the participants in using the planning time more strategically, which led them to produce more accurate and adequate speech performances; (2) The isolated strategy instruction seemed to produce a stronger effect on the planned speech performance, which may be related to the amount of attention that this type of instruction required from the participants; (3) Instruction might have led the participants to focus their attention on form, considering that one's primary attention focus is on meaning (VanPattern, 1990); (4) Adequacy seemed to be a fair measure to assess more discourse-oriented aspects of speech performance, such as structure, appeal, clarity, vocabulary, and fluency perception, which legitimates it as a new dimension of speech performance.

Such conclusions are important findings that may bring contributions to the strategic planning and strategy instruction fields. Strategic planning is an interesting construct to assess and investigate speech performance, and it is important to ensure that learners are using it properly in order to obtain reliable results. Strategy instruction may be a pedagogical tool that enhances the planning time and leads learners to reflect and be aware of what they have to do while they plan their tasks.

In spite of the illuminating results, other studies should be conducted in order to examine the variables brought by this study. It would be interesting to adopt a non-planning condition, for example, different participants with different levels of proficiency, and/or different educational contexts.

\section{Notes}

1. Undetailed and detailed planning are also terms used to refer to unguided and guided planning.

2. Even though there is an effort made by SLA researchers to inform LP, Ellis (1997) explains that SLA and LP are different areas with particular research agendas. That means that claims brought by SLA studies should be carefully concerned.

3. Level-5 groups generally consist of intermediate students, who are placed in this level after taking a placement test or after studying English for 4 semesters. However, it is common for some students in these classes to be below the proficiency level that is expected from them. Therefore, a decision was made to 
include only those students in the three classes who scored intermediate in an oral proficiency test.

4. As the integrated strategy instruction is embedded in the regular lessons, there are more variables to be controlled such as learners' attendance. If learners miss lessons, it is necessary to consider whether you shall use him/her as a participant.

5. This number represents the index of subordination in the speech sample. The calculation was provided by dividing the number of independent and dependent clauses by the number of AS-units. If the index number is 1, it means that the story does not have any subordination - and the higher this number, the higher the number of subordination in the story.

6. Notes from our research diary.

\section{References}

Cohen, A. D. (1998). Strategies in learning and using a second language. New York: Longman.

D'Ely, R. (2006). A Focus on learners' metacognitive processes: the impact of strategic planning, repetition, strategic planning plus repetition, and strategic planning for repetition on L2 oral performance. Unpublished Doctoral Thesis. Universidade Federal de Santa Catarina. Florianópolis.

D'Ely, R. (2011). The impact of familiarity with strategic planning and teacher-led planning on learners' L2 oral performance of focused and unfocused tasks. In Tumolo, C., Figueiredo, D., Moritz, M., \& D`Ely, R. Contextualized Practices in EFL Teaching and Assessment (pp. 99 - 152). Florianópolis: PGI-UFSC.

D’Ely, R. \& Weissheimer, J. (2004). Scale of L2 oral proficiency. Unpublished research paper. Universidade Federal de Santa Catarina, Florianópolis.

Dörnyei, Z. (2005). The psychology of the language learner: Individual differences in second language acquisition. Mahwah, NJ: Lawrence Erlbaum.

Ellis, R. (2005). Planning and task-based performance: Theory and research. In R. Ellis (Ed.), Planning and task performance in a second language (pp. 3-34). Philadelphia: John Benjamins.

Ellis, R. (2009). The differential effects of three types of task planning on the fluency, complexity, and accuracy in L2 oral production. Applied Linguistics, 30, 474-509.

Foster, P. \& P. Skehan. (1996). The influence of planning on performance in taskbased learning, Studies in Second Language Acquisition 18/3: 299-324.

Foster, P., \& Skehan, P. (1999). The influence of source of planning and focus of planning on task-based performance. Language Teaching Research, 3, 215-247.

Guará -Tavares, M. G. (2008). Pre-task Planning, Working Memory Capacity and L2 Speech Performance. Unpublished Doctoral Thesis, Universidade Federal de Santa Catarina, Brazil.

Guará-Tavares, M.G. (2016). Learners' processes during pre-task planning and Working Memory Capacity. Ilha do Desterro, 68(1), 79-94.

Kawauchi, C. (2005). The effects of strategic planning on the oral narratives of learners with low and high intermediate L2 proficiency. In R. Ellis (Ed.), Planning and task performance in a second language (pp. 143-164). Amsterdam: John Benjamins.

Long, M. (1991). Focus on form: a design feature in language teaching methodology. Foreign language research in cross-cultural perspective (pp 39-52). De Bot, K,Gensberg, R \& Kramsch, C. (Eds).. John Benjamins Publishing Company. Amsterdam/Philadelphia. 
Mehnert, U. (1998). The effects of different lengths of time for planning on second language performance. Studies in Second Language Acquisition 20: 52-83.

Ortega, L. (1999). Planning and focus on form in L2 oral performance, Studies in Second Language Acquisition 21: 109-48.

Ortega, L. (2005). What do learners plan? Learner-driven attention to form during pretask planning. In Ellis, R. (Ed.) Planning and Task performance in a second language). Language learning and language teaching. Vol. 11. Amsterdam/ Philadelphia: John Benjamins Publishing Company, pp. 77-109.

Oxford, R. (1990). Language learning strategies: What every teacher should know. New York: Newbury House/ Harper \& Row.

Oxford, R. (2011). Teaching and Researching Language Learning Strategies. Harlow: Pearson Education.

Pallotti, G. (2009). CAF: Defining, refining and differentiating constructs. Applied Linguistics, 30/4, pp. 590-601.

Pang F., Skehan P. (2014). Self-reported planning behaviour and second language performance in narrative retelling. In: Skehan P. (Ed.), Processing perspectives on task performance (pp. 95-127). Amsterdam: John Benjamins.

Robinson, P. (1995). Task Complexity and second Language Narrative Discourse. Language Learning 45:(1), 99-140.

Sangarun, J. (2005). The effects of focusing on meaning and form in strategic planning. In Ellis, R. (Ed.) Planning and Task performance in a second language). Language learning and language teaching. Vol. 11. Amsterdam/Philadelphia: John Benjamins Publishing Company, pp. 111-142.

Schmidt, R (2001). Attention. In P. Robinson (Ed.), Cognition and second language instruction. Cambridge University Press, pp. 3-32.

Skehan, P. (2014). The context for researching a processing perspective on task performance. In: Skehan P. (Ed.), Processing perspectives on task performance (pp. 95-127). Amsterdam: John Benjamins.

Skehan, P. (2016). Tasks versus conditions: Two perspectives on task research and their implications for pedagogy. Annual Review of Applied Linguistics, 36, 34-49.

Skehan, P. \& Foster, P. (1996). Task type and task processing conditions as influences on foreign language performance. Thames Valley University Working Papers in English Language Teaching, 3, pp. 139-188.

Skehan, P. \& Foster, P. (2001). Cognition and tasks. In Robinson, P. (Ed.), Cognition and second language instruction, pp. 183-205. Cambridge: Cambridge University Press.

Specht, A. L. (2015). Tasks and proficiency tests: Piloting instruments of a study on strategic planning. Unpublished research paper. Universidade Federal de Santa Catarina, Florianópolis.

Specht, A. L. \& D'Ely, R. (2017). Planning oral narrative tasks: optimizing strategic planning condition through strategy instruction. Acta Scientiarum, 39(2): 203212.

Trendak, O. (2015). Exploring the Role of Strategic Intervention in Form-focused Instruction. Springer International Publishing, Switzerland.

VanPatten, B. (1990). Attending to Form and Content in the Input. Studies in Second Language Acquisition, 12(3), 287-301. 